\title{
Selected Topics on Information Logistics: Editorial Introduction to the Issue 2 of CSIMQ
}

\author{
Kurt Sandkuhl \\ University of Rostock, Chair Business Information Systems, \\ Albert-Einstein-Str. 22, 18059 Rostock, Germany \\ Kurt Sandkuhl@uni-rostock.de
}

While the amount of information relevant for enterprises and organizations grows ever more, the decisions and operational tasks depending on information are becoming more complex. Accurate and readily available information is indispensable in problem solving, decision-making, and knowledge-intensive work. Studies on information use show that information overload is perceived as a problem in organizations and enterprises (see, e.g. [1], [2]). IT-solutions or organizational measures to support supply of the "right" information does not only have to take into account the relevance of the "content", but also to understand the context of the task or decision at hand and how to tailor content accordingly. In particular, knowledge-intensive industry and service sectors, public organizations and governmental bodies are dependent on accurate and timely information supply for efficient and high quality processes and services. Intelligent information supply has become an important issue that is characterized by just-intime, demand-oriented and context-sensitive information.

The field of information logistics has been addressing the above mentioned challenge for more than a decade by using principles from material logistics, like just-in-time delivery, for the provision of information. In general, information logistics explores, develops, and implements concepts, methods, technologies, and solutions for the above mentioned purpose. During the last decade, research work in information logistics addressed various aspects of demand-oriented information supply, including

- methodical aspects, like a method for information demand analysis in an enterprise context [3],

- the reuse of proven knowledge about information logistics solutions, like patterns of information demand for efficiently constructing solutions [4],

- frameworks for structuring information logistics in applications area, e.g., information logistics in business intelligence [5],

- technologies for implementing intelligent solutions in information logistics, like for context and situation-awareness [6], and

- applications in many fields, like in tele-medicine [7] or media industries [8].

The content of this issue presents novel four research results in information logistics and knowledge supply represented by the best papers of the 7th International Workshop on Information Logistics (ILOG) which took place in Lund (Sweden) in September 2014 and the paper on the bibliometric analysis of performance modeling. The focus of the ILOG workshop series is on advances in information logistics as a forum for sharing knowledge and experiences between the academic community and practitioners from industry and the public sector. ILOG was initiated in 2005; since its foundation it has been hosted in Sweden (2005, 2014), Germany (2006, 2009), Latvia (2011), Russia (2012) and Poland (2013). 
The five accepted papers address different technical and methodic aspects of information logistics and different application fields:

- Alksnis, Asnina, Kirikova and Meiers address the subject of how to share knowledge between people and business and specifically focus on enabling support of collaborative cross-enterprise business processes for legacy ERP systems.

- Abbate, Bassano, D'Aniello, Miranda, Perano, Piciocchi and Rarità present an approach how to improve knowledge-based decision support systems for public administrations by using mechanisms of value co-creation.

- Stamer, Ponomarev, Shilov and Smirnov investigate the use of information demand patterns and a collaborative recommendation system for improving e-mail communication. The focus of this paper is on technical aspects of the implementation.

- Jugel, Schweda, Zimmermann and Läufer position their paper in Enterprise Architecture Management (EAM) and investigate to what extent existing EAM tools offer visual analytics features, e.g., how they support organizational stakeholders in visualizing the "right" information for decision-making tasks.

- Livieri, Di Cagno and Bochicchio perform a bibliometric analysis in the field of performance modeling. Performance indicators are considered as a prerequisite to make informed decisions in enterprises. The results of the analysis are intended to contribute to digital business and model-driven enterprises.

The CSIMQ editorial team would like to thank the reviewers of this issue for providing valuable comments and improvement proposals for the submitted papers.

\section{References}

[1] R. Winter, Enterprise-wide information logistics: Conceptual foundations, technology enablers, and management challenges. In Information Technology Interfaces, 2008. ITI 2008. 30th International Conference on IEEE. June 2008, pp. 41-50 http://dx.doi.org/10.1109/ITI.2008.4588382

[2] A. Öhgren, and K. Sandkuhl, Information Overload in Industrial Enterprises. Results of an Empirical Investigation. In 2nd European Conference on Information Management and Evaluation. Reading: Academic Publishing, 2008.

[3] M. Lundquist, K. Sandkuhl and U. Seigerrroth, Modelling Information Demand in an Enterprise Context: Method, Notation and Lessions Learned, in International Journal Systems Modeling and Design, Vol. 2(3), IGI Publishing, 2011, pp.74-96. http://dx.doi.org/10.4018/jismd.2011070104

[4] K.Sandkuhl, Information Demand Patterns, in Proc. PATTERNS 2011, The Third International Conference on Pervasive Patterns and Applications, Sept. 25-30, 2011, Rome, IT.

[5] B. Dinter, and R. Winter, Information Logistics Strategy-Analysis of Current Practices and Proposal of a Framework. In Proc. the 42nd Hawaii International Conference on System Sciences, Los Alamitos: IEEE Computer Society, 2009. http://dx.doi.org/10.1109/HICSS.2009.253

[6] U. Meissen, S. Pfennigschmidt, A. Voisard, and T. Wahnfried, Context-and situation-awareness in information logistics. In Current Trends in Database Technology-EDBT 2004 Workshops, Berlin, HDB: Springer, pp. 335-344. http://dx.doi.org/10.1007/978-3-540-30192-9_33

[7] S. Meister, and V. Stahlmann, Telemedial ILOG Listeners. Information Logistics Processing of Telemedical Values Using CEP and HL7. in Ambient Assisted Living 2012, Berlin, HDB: Springer. http://dx.doi.org/10.1007/978-3-642-27491-6_18

[8] A. Billig, E. Blomqvist, and F. Lin. Semantic Matching based on Enterprise Ontologies. In Proc. the 6th International Conference on Ontologies, DataBases, and Applications of Semantics. Berlin, HDB: Springer, 2007. http://dx.doi.org/10.1007/978-3-540-76848-7_76 